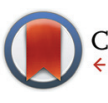

CrossMark \&lick for updates

Cite this: Dalton Trans., 2016, 45 1055

Received 27th August 2015,

Accepted 11th November 2015

DOI: $10.1039 / c 5 d t 03324 a$

www.rsc.org/dalton

\section{Aluminum borate nanowires from the pyrolysis of polyaminoborane precursors $\uparrow$}

\author{
Van An Du, \$ Titel Jurca, \$ George R. Whittell* and Ian Manners* \\ Polyaminoboranes $\left[\mathrm{N}(\mathrm{R}) \mathrm{H}-\mathrm{BH}_{2}\right]_{n}(\mathbf{1}: \mathrm{R}=\mathrm{H}, \mathbf{2}: \mathrm{R}=\mathrm{Me})$ were pyrolyzed on a range of substrates: silicon, \\ metal foils (stainless steel, nickel, and rhodium), and sapphire wafers, as well as on $\mathrm{Al}_{2} \mathrm{O}_{3}$ and AIN \\ powders. The pyrolysis of $\mathbf{2}$ on a Si-wafer resulted in porous nanostructures containing hexagonal-boron \\ nitride (h-BN). In the case of 1 or $\mathrm{H}_{3} \mathrm{~N} \cdot \mathrm{BH}_{3}$ as precursor, using rhodium foil as substrate afforded amor- \\ phous $\mathrm{B}$ and $\mathrm{N}$-containing nanostructures, and polydisperse spherical nanoparticles, respectively. Switch- \\ ing the substrate to sapphire wafers, as well as to $\mathrm{Al}_{2} \mathrm{O}_{3}$ or $\mathrm{AIN}$ powders, resulted in formation of \\ crystalline $\mathrm{Al}_{5} \mathrm{BO}_{9}$ nanostructures (nanowires, nanotubes, and nanoribbons). For sapphire wafers, the size \\ of the resulting nanowires was influenced by modifying the surface defect density.
}

\section{Introduction}

Over the past decade, the intense interest in amine-boranes as hydrogen storage materials ${ }^{1}$ has led to a broad exploration of other aspects of amine-borane chemistry. This has fostered new uses for amine-boranes as reducing and hydrogen transfer agents, ${ }^{2}$ and recently as substrates in the transition-metal catalyzed synthesis of inorganic boron-containing polymers that may possess novel materials properties. ${ }^{3}$

Boron nitride $(\mathrm{BN})$ in its various forms (e.g. nanotubes, nanowires, atomically thin films) features high thermal stability, high mechanical strength, resistance to both corrosion and oxidation, as well as useful electrical properties, such as high resistance and low dielectric constant. ${ }^{4}$ Since the discovery of graphene in $2004,{ }^{5}$ hexagonal boron nitride (h-BN), the BN-based structural equivalent of graphite, has garnered much attention. Whereas single layers of graphite (graphene) have zero band gap, h-BN is a wide-band gap semiconductor $(\sim 6 \mathrm{eV})$ with promising applications in UV lasing and as a dielectric. ${ }^{6}$ Hexagonal boron nitride materials are typically prepared by vapour deposition, condensed-phase pyrolysis of molecular reagents, or preceramic polymer routes. $^{6 c, 7}$

Due to their high gravimetric content of boron and nitrogen (ca. $80 \%$ for $\mathrm{H}_{3} \mathrm{~N} \cdot \mathrm{BH}_{3}$ ), which is already intimately pre-mixed in the required 1:1 ratio, amine-boranes are an attractive, potential single-source precursor to BN materials. ${ }^{7 f, g}$ Polybora-

School of Chemistry, University of Bristol, Bristol, BS8 1TS, UK.

E-mail:ian.manners@bristol.ac.uk,g.whittell@bristol.ac.uk

$\dagger$ Electronic supplementary information (ESI) available. See DOI: 10.1039/ c5dt03324a

$\$$ These authors contributed equally to this work. zylenes, ${ }^{7 i, j}$ which have been used as precursors to BN-based ceramics, and other boron-nitrogen containing polymers, such as polyaminoboranes, ${ }^{3}$ have similar attributes, along with the advantage of easy scale up and facile macromolecular processing. $^{7 f-k}$ Herein, we report the pyrolysis of polyaminoboranes $\left[\mathrm{N}(\mathrm{R}) \mathrm{H}-\mathrm{BH}_{2}\right]_{n}(\mathbf{1}: \mathrm{R}=\mathrm{H}, \mathbf{2}: \mathrm{R}=\mathrm{Me})$ on a range of substrates: silicon, metal foils (stainless steel, nickel, and rhodium), and sapphire wafers, as well as $\mathrm{Al}_{2} \mathrm{O}_{3}$ and $\mathrm{AlN}$ powders. The pyrolysis of polyaminoboranes on Si-wafers and rhodium foil afforded BN-containing nanostructures. However, sapphire wafers, as well as $\mathrm{Al}_{2} \mathrm{O}_{3}$ and AlN powders resulted in the formation of aluminum borate nanomaterials. As discussed below, the latter material is of interest for a range of potential applications as a high performance ceramic.

\section{Experimental}

\section{General procedures}

Reactions were performed under nitrogen or argon using dry solvents. All chemicals were purchased from Aldrich and used as received unless otherwise noted. Silicon and sapphire wafers were purchased from Wafer World, and Roditi International, respectively. Ammonia borane was obtained from Aldrich and purified by sublimation $\left(T=40^{\circ} \mathrm{C}, p=10^{-3} \mathrm{mbar}\right)$ prior to use. THF was dried using a Grubb's solvent purification system. ${ }^{8}$ Dehydropolymerization catalyst $\mathrm{Ir}-\mathrm{H}_{2} \mathrm{POCOP}$ (POCOP $=2,6$-bis(di-tertbutylphosphinito)-benzene) was synthesized according to the literature. ${ }^{9}$ Polyaminoboranes $(\mathbf{1}$ and 2) were synthesized according to the iridium-catalyzed method as previously described in the literature (Scheme 1). ${ }^{3 b, c}$

Polymers were precipitated at $-78{ }^{\circ} \mathrm{C}$ in $n$-pentane. Isolated polyaminoborane 2 was found to have $M_{\mathrm{n}}=54000 \mathrm{~g} \mathrm{~mol}^{-1}$, 


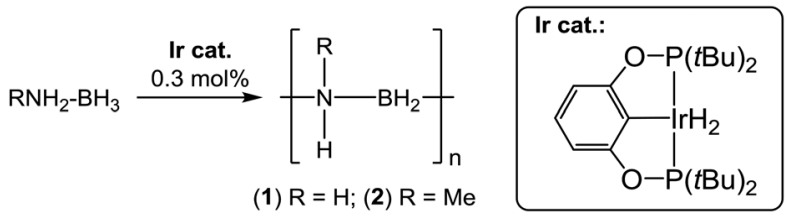

Scheme 1 Synthesis of polyaminoboranes 1 and 2 .

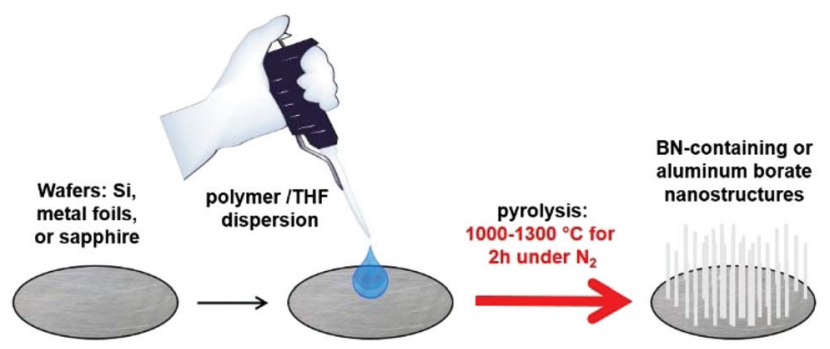

Fig. 1 Preparation and growth of nanostructures from BN-containing precursors on silicon, metal foil or sapphire wafers.

and PDI $=1.32$ by GPC. Polymers or $\mathrm{H}_{3} \mathrm{~N} \cdot \mathrm{BH}_{3}$ were dropcast from $2 \mathrm{mg} \mathrm{mL} \mathrm{mL}^{-1}$ solutions/dispersions in THF onto the respective substrates: silicon, metal foil \{stainless steel (composition $\mathrm{Fe}: \mathrm{Cr}: \mathrm{Ni}$; 70:19:11 wt\%), nickel, and rhodium\}, and sapphire wafers. Additional experiments were conducted with $1: 1$ by mass mixtures of 1 with $\mathrm{Al}_{2} \mathrm{O}_{3}$ or AlN powders. Pyrolysis experiments were carried out in a horizontal carbolite tube furnace (type 3508), within a $74 \mathrm{~mm}$ (outer diameter) by

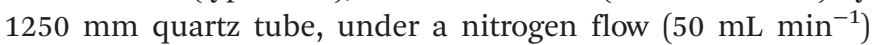
with a heating rate of $10^{\circ} \mathrm{C} \mathrm{min}^{-1}$ to $1000-1300{ }^{\circ} \mathrm{C}$. The time required to heat to these temperatures is included in the pyrolysis time given (Fig. 1).

\section{Equipment}

Conventional calibration gel permeation chromatography (GPC-CC) measurements were carried out at $35{ }^{\circ} \mathrm{C}$ at a flow rate of $1.0 \mathrm{~mL} \mathrm{~min}{ }^{-1}$ in $n \mathrm{Bu}_{4} \mathrm{NBr} / \mathrm{THF}\left(0.1 \mathrm{wt} \% n \mathrm{Bu}_{4} \mathrm{NBr}\right)$ on a Viscotek GPCmax equipped with both a UV-Vis detector operating at $450 \mathrm{~nm}$ and differential refractometer. The column was calibrated with polystyrene standards. Samples were dissolved in THF (1.00 mg mL $\mathrm{mL}^{-1}$ unless otherwise stated) and filtered with Ministart SRP 15 filters (pore size $0.45 \mu \mathrm{m}$ ) prior to analysis. For powder X-ray diffraction measurements, the samples were placed onto a silicon wafer and data were collected with $\mathrm{Cu}-\mathrm{K} \alpha$ radiation $(\lambda=1.5418 \AA)$ on a Bruker D8 Advance powder diffractometer fitted with a $2 \mathrm{~mm}$ fixed divergence slit. Data were collected between $10-50$ or $10-100$ degrees $2 \theta$ in $\theta / 2 \theta$ mode with a step width of $0.5^{\circ}$. Thermogravimetric analysis (TGA) was performed on a TA Instruments Q500 thermogravimetric analyzer from 20 to $1000{ }^{\circ} \mathrm{C}$ at a scan rate of $10{ }^{\circ} \mathrm{C} \min ^{-1}$ under a flow of $\mathrm{N}_{2}$.

The samples for electron microscopy were prepared by drop casting one drop of suspension of the sample in $\mathrm{MeOH}$ onto a carbon coated copper grid which was placed on a piece of filter paper to remove excess solvent. Bright field transmission electron microscopy (TEM) micrographs were obtained on a JEOL 1200 Mk2 TEM microscope operating at $120 \mathrm{kV}$ and equipped with an SIS MegaViewIII digital camera. High resolution images were recorded with a Gatan ORIUS Digital Camera in a JEOL Hi Resolution TEM 2011. Energy-dispersive X-ray (EDX) spectra (spot size of $35 \mathrm{~nm}$ ) were obtained with an Oxford Instruments ISIS 310 system equipped with a ATW Si (Li) X-ray detector. Scanning electron microscope (SEM) measurements were carried out with a JEOL SEM 5600 LV and a JEOL Field Emission Gun SEM 6330. The samples were mounted onto a sample stub using double sided carbon tape and coated with Ag (15-20 nm). Wavelength-Dispersive X-Ray Spectroscopy (WDS) experiments were carried out with a JEOL JXA8530F Hyperprobe Electron Probe Microanalyser (EPMA) with 5 wavelength dispersive spectrometers and a SDD-EDS (silicon drift detector energy dispersive spectrometer) detector. Operating conditions: (for polymer pyrolyzed on AlN) $5 \mathrm{kV}$, $100 \mathrm{nA}$ and $10 \mu \mathrm{m}$ beam, (for polymer pyrolyzed on $\mathrm{Al}_{2} \mathrm{O}_{3}$ ) $5 \mathrm{kV}, 150 \mathrm{nA}$ and $1 \mu \mathrm{m}$ beam, and (remaining samples) $5 \mathrm{kV}$, $150 \mathrm{nA}$, and $10 \mu \mathrm{m}$ beam.

\section{Results}

\section{Thermogravimetric analysis of polyaminoboranes 1 and 2}

The TGA thermogram of $\mathbf{1}$ indicated thermal stability up to $170{ }^{\circ} \mathrm{C}$, during which a mass loss of only $2 \%$ was observed. Past this temperature, sharp decomposition ensued, which was complete by $210{ }^{\circ} \mathrm{C}$ and accounted for a $60 \%$ mass loss. Continued heating to $1000{ }^{\circ} \mathrm{C}$ resulted in minimal further decomposition, giving an ultimate ceramic yield of $34 \%$ (Fig. S1a $\dagger$ ). In a similar manner, the TGA thermogram of 2 indicated stability to mass loss up to $100{ }^{\circ} \mathrm{C}$, after which an $8 \%$ mass loss ensued up to $140{ }^{\circ} \mathrm{C}$, followed by sharp decomposition by $150{ }^{\circ} \mathrm{C}$, resulting in $80 \%$ total mass loss. Continued heating to $1000{ }^{\circ} \mathrm{C}$ gave an ultimate ceramic yield of $16 \%$ (Fig. S1b $\dagger$ ). Based on these results, we performed pyrolysis of $\mathbf{1}$ and $\mathbf{2}$ on a preparative scale with a variety of substrates under similar conditions $\left(1000{ }^{\circ} \mathrm{C}\right.$ under flow of $\left.\mathrm{N}_{2}\right)$.

\section{Pyrolysis of polyaminoboranes 1 and 2 on silicon wafers}

Initial work focused on the attempted formation of BN-containing nanostructures by pyrolysis of polyaminoboranes $\mathbf{1}$ and 2 on silicon wafers. These surfaces are relatively unreactive, thus providing an opportunity to study the high-temperature chemistry of $\mathbf{1}$ and $\mathbf{2}$ independent of substrate effects. Attempted pyrolysis $\left(2 \mathrm{~h}\right.$, at $1000^{\circ} \mathrm{C}$ under flow of $\mathrm{N}_{2}$ ) of $\mathbf{1}$ was unsuccessful, leading to depolymerisation and resulting in only trace amounts of material on the wafer post-pyrolysis. Analogous treatment of 2, however, resulted in the formation of a material that exhibited micron-scale porosity due to the presence of nanoscale fibres (Fig. S2 $\dagger$ ). ${ }^{10}$ XRD revealed a high intensity reflection at $2 \theta=27.8^{\circ}$ and one of lower intensity at $2 \theta=40.9^{\circ}$ (Fig. S3†) which could be indexed to the $\left(\begin{array}{lll}0 & 0 & 2\end{array}\right)$ and 
(1 $\left.\begin{array}{lll}1 & 0\end{array}\right)$ lattice planes of h-BN, respectively (ICSD: 168892). The presence of $\mathrm{B}$ and $\mathrm{N}$ (in addition to $\mathrm{C}$ and $\mathrm{O}$ ) was suggested by SEM-EDX (Fig. S4 $\dagger$ ).

The use of a Si-substrate also appeared to exert an influence on the ceramic yield. The samples obtained from the pyrolysis of 2 in a ceramic combustion crucible displayed a ceramic yield of $8 \%$, while those obtained on a Si-wafer showed a nearly ten-fold increase to $77 \%$. We postulate that this may be due to an anchoring effect facilitated by reaction between the $\mathrm{B}-\mathrm{H}$ bonds of the polymer and the $-\mathrm{OH}$ groups on the surface of the Si-wafer.

\section{Pyrolysis of polyaminoboranes 1 and 2 on metal foils}

We then turned our attention to the pyrolysis of polyaminoboranes 1 and 2 on metal foils; namely stainless-steel (composition Fe:Cr:Ni; 70:19:11 wt\%) and nickel (99\%). The precedents established for the heterogeneous catalytic dehydrocoupling of amine-boranes by both iron, and nickel-based catalysts make these metal foils intriguing as both substrates and catalysts for the formation of extended $\mathrm{BN}$ nanostructures from amine-borane based precursors. ${ }^{11}$ Moreover, there are multiple examples of BN nanostructures being grown from both stainless steel and nickel substrates utilizing alternative precursors. ${ }^{12}$ However, in the case of $\mathbf{1}$ and 2, neither substrate proved successful. Pyrolysis $\left(2 \mathrm{~h}\right.$, at $1000{ }^{\circ} \mathrm{C}$ under flow of $\mathrm{N}_{2}$ ) of 1 on stainless-steel foil resulted in the formation of micronsized needles that appear to grow from the surface (Fig. S5 $\dagger$ ). Pyrolysis of 1 on nickel foil, however, afforded platelets that were polydisperse in size but predominately $>1 \mu \mathrm{m}$ in the shortest observed dimension (Fig. S6†). In neither case were B- and N-containing materials detected by EDX (see Fig. S7 and $\mathrm{S} 8 \dagger$ ). In both instances, the structures were most probably comprised of metal oxides. ${ }^{13}$

There is also extensive precedence for heterogeneous catalytic dehydrocoupling of amine-boranes by rhodium-based catalysts. $^{3 e, 14}$ This prompted a similar study into the applicability of $\mathrm{Rh}$ foil as both a substrate and catalyst for the formation of extended $\mathrm{BN}$ nanostructures utilizing amine-boranes as precursors. Pyrolysis $\left(2 \mathrm{~h}\right.$, at $1000{ }^{\circ} \mathrm{C}$ under flow of $\left.\mathrm{N}_{2}\right)$ of both 1 and 2 on $0.025 \mathrm{~mm} \mathrm{Rh}$ foil resulted in the formation of nanostructures (Fig. 2a and b for 1), which were found to contain $\mathrm{B}$ and $\mathrm{N}$ (in addition to $\mathrm{C}$ and $\mathrm{O}$ ) by SEM-EDX (Fig. S9†). No Bragg reflections were observed by XRD for these samples, which is consistent with an amorphous structure.

Pyrolysis of $\mathrm{H}_{3} \mathrm{~N} \cdot \mathrm{BH}_{3}$, the precursor to 1 , on $0.025 \mathrm{~mm} \mathrm{Rh}$ foil resulted in the formation of spherical nanoparticles (Fig. 2c and d), which were confirmed to contain $\mathrm{B}$ and $\mathrm{N}$ by SEM-EDX (Fig. S10†). The particles were polydisperse in size, with diameters ranging from 40-205 $\mathrm{nm}$ (Fig. 2c and d). They were, however, difficult to remove from the Rh foil, thus hampering a more thorough study by high-resolution TEM (Fig. 2d). Attempted characterization by XRD and TEM revealed that they are likely amorphous in structure and more polydisperse in size than previously reported examples of spherical BN-containing nanoparticles. ${ }^{15}$ Conventional methods for growth of spherical BN-containing nanoparticles rely on more

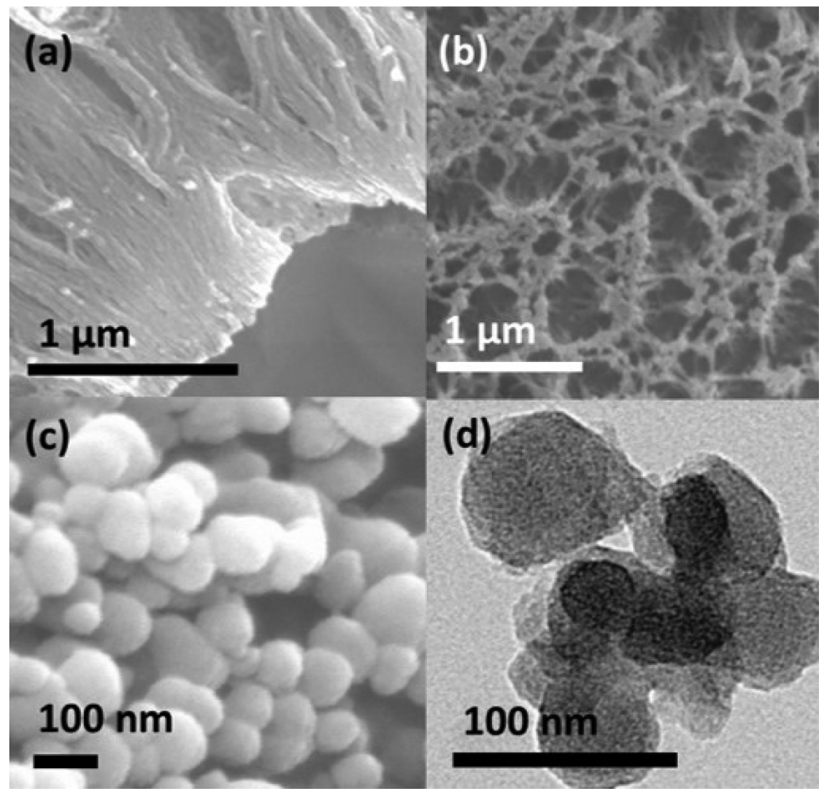

Fig. 2 Electron microscopy images of ( $a, b$, SEM images) amorphous $B$ and $\mathrm{N}$-containing nanostructures grown from pyrolysis $\left(2 \mathrm{~h}\right.$, at $1000{ }^{\circ} \mathrm{C}$ under flow of $\mathrm{N}_{2}$ ) of polyaminoborane 1 on rhodium foil, and (c, SEM image, d, TEM image) spherical nanoparticles grown from the pyrolysis ( $2 \mathrm{~h}$, at $1000^{\circ} \mathrm{C}$ under flow of $\mathrm{N}_{2}$ ) of $\mathrm{H}_{3} \mathrm{~N} \cdot \mathrm{BH}_{3}$ on rhodium foil.

complex aerosol assisted, or chemical vapour deposition (CVD) methodology utilizing multicomponent precursors. ${ }^{15}$

\section{Pyrolysis of polyaminoboranes 1 and 2 on sapphire wafers}

As sapphire substrates have previously been utilized for the growth of polycrystalline h-BN via metal organic chemical vapour deposition (MO-CVD) of triethylborane and ammonia at $750-1200{ }^{\circ} \mathrm{C},{ }^{16}$ we expected sapphire wafers to facilitate the conversion of polyaminoboranes 1 and 2 to h-BN via pyrolysis. However, the pyrolysis $\left(2 \mathrm{~h}\right.$, at $1000{ }^{\circ} \mathrm{C}$ under flow of $\left.\mathrm{N}_{2}\right)$ of polyaminoborane $\mathbf{1}$ on sapphire wafer resulted in the formation of aluminum borate nanowires. The resulting wires grew in high density, and appeared as rough-surfaced rectangular prisms of various lengths and with widths in the range of 100-150 $\mathrm{nm}$ (Fig. 3).

In a similar experiment employing a mixture of $\mathrm{B}$ and $\mathrm{B}_{2} \mathrm{O}_{3}$ as the feedstock, these species were comprised predominately of $\mathrm{Al}_{5} \mathrm{BO}_{9}$, but with a small component of $\mathrm{Al}_{4} \mathrm{~B}_{2} \mathrm{O}_{9}$, as determined by XRD. ${ }^{17 a}$ Unfortunately, the similarity of the two aluminium borate structures, and the relatively low quality of our XRD data (Fig. 4) precludes such a distinction from being made. Having performed the pyrolysis under similar conditions to that with $\mathrm{B} / \mathrm{B}_{2} \mathrm{O}_{3}$, however, and employing a relatively boron-poor precursor, it would appear most likely that we too have formed the aluminium-rich phase predominantly, namely $\mathrm{Al}_{5} \mathrm{BO}_{9}$. Thus, the four reflections at $2 \theta=16.7,17.0$, 26.7 and $33.7^{\circ}$ were indexed to the (lll $\left.\begin{array}{lll}0 & 2 & 1\end{array}\right),\left(\begin{array}{lll}1 & 1 & 0\end{array}\right),\left(\begin{array}{lll}1 & 3 & 1\end{array}\right)$ and $\left(\begin{array}{lll}1 & 3 & 2\end{array}\right)$ planes of the orthorhombic phase of $\mathrm{Al}_{5} \mathrm{BO}_{9}$ (ICSD: 039013). It is noteworthy, however, that the intense reflection 

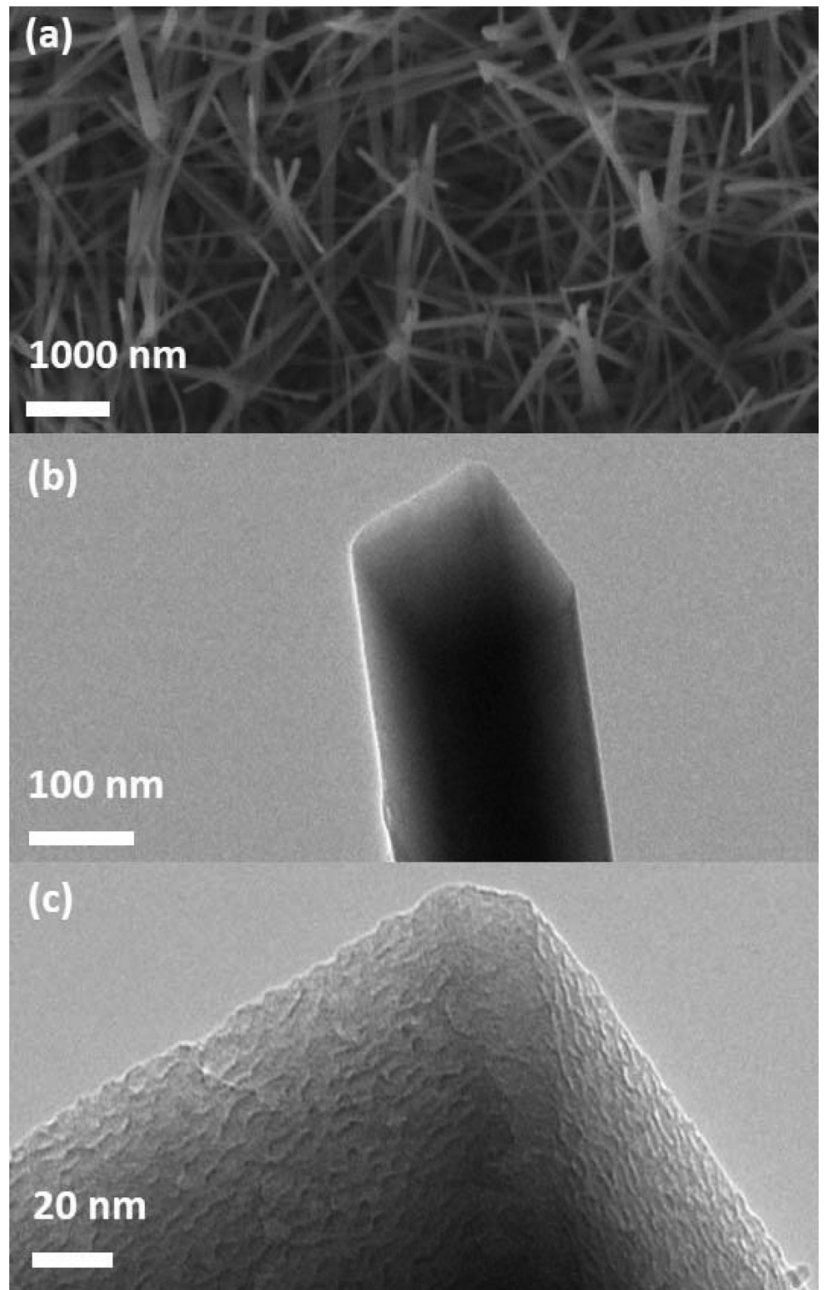

Fig. 3 Electron microscopy images of $\mathrm{Al}_{5} \mathrm{BO}_{9}$ nanowires grown by pyrolysis $\left(2 \mathrm{~h}\right.$, at $1000{ }^{\circ} \mathrm{C}$ under flow of $\mathrm{N}_{2}$ ) of polyaminoborane 1 on sapphire with defects; (a) SEM image, (b) and (c) TEM images of a single $\mathrm{Al}_{5} \mathrm{BO}_{9}$ nanowire.

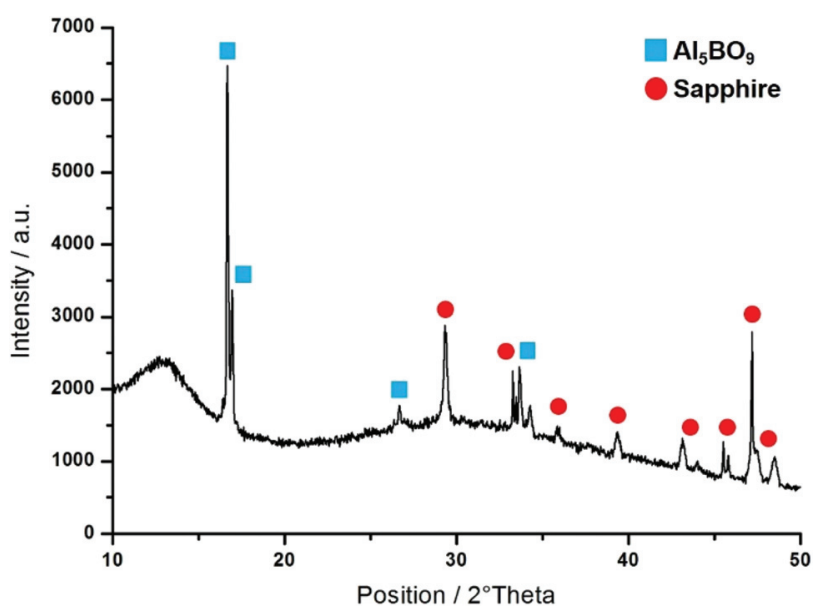

Fig. 4 XRD measurement of $\mathrm{Al}_{5} \mathrm{BO}_{9}$ nanowires grown by pyrolysis ( $2 \mathrm{~h}$, at $1000^{\circ} \mathrm{C}$ under flow of $\mathrm{N}_{2}$ ) of 1 on sapphire with defects.

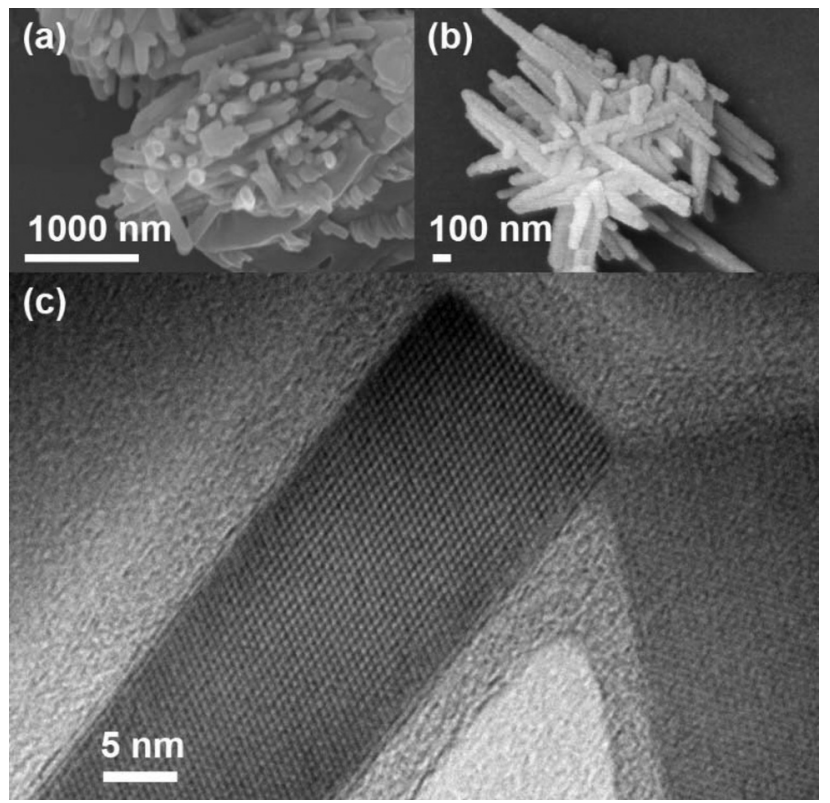

Fig. 5 Electron microscopy images of $\mathrm{Al}_{5} \mathrm{BO}_{9}$ nanowires grown from the pyrolysis $\left(2 \mathrm{~h}\right.$, at $1000{ }^{\circ} \mathrm{C}$ under flow of $\left.\mathrm{N}_{2}\right)$ of a (1:1 by mass) mixture of $\mathrm{Al}_{2} \mathrm{O}_{3}$ powder and polyaminoborane 1. (a), (b) SEM images, and (c) high resolution TEM image of a single $\mathrm{Al}_{5} \mathrm{BO}_{9}$ nanowire.

expected at $2 \theta=20.4^{\circ}$, arising from the (llll 11 ) plane was not observed. We attribute this phenomenon to the orientation of the nanowires with respect to the substrate, and note that this was also the case when $\mathrm{B} / \mathrm{B}_{2} \mathrm{O}_{3}$ feedstock was employed. The presence of $\mathrm{Al}, \mathrm{B}$, and $\mathrm{O}$ was confirmed by TEM-EDX and WDS measurements (Fig. S11 and S12†). Nucleation and nanowire growth appears to occur along defects, ${ }^{17}$ and thus optimized conditions included introducing defects on the sapphire wafer by scratching the surface with a diamond-tip knife prior to drop-casting the THF dispersion of 1.

Pyrolysis $\left(2 \mathrm{~h}\right.$, at $1000{ }^{\circ} \mathrm{C}$ under flow of $\left.\mathrm{N}_{2}\right)$ of a $(1: 1$ by mass) mixture of $\mathrm{Al}_{2} \mathrm{O}_{3}$ powder and polyaminoborane $\mathbf{1}$ also resulted in the formation of clusters of aluminum borate nanowires (Fig. 5). High resolution TEM revealed nanowires with diameters as small as $30 \mathrm{~nm}$ (Fig. 5c). In this instance, the XRD diffraction pattern (Fig. S13†) was in agreement with the standard powder diffraction pattern of orthorhombic $\mathrm{Al}_{5} \mathrm{BO}_{9}$ (ICSD: 039013), including the observation of the $\left(\begin{array}{lll}1 & 1 & 1\end{array}\right)$ reflection that was absent for the measurement performed on sapphire. Moreover, the lattice fringes observed in Fig. $5 \mathrm{c}$ and S14† featured a $d$-spacing of $0.44 \mathrm{~nm}$, and were indexed to the $\left(\begin{array}{lll}1 & 1 & 1\end{array}\right)$ plane of $\mathrm{Al}_{5} \mathrm{BO}_{9}$ (ICSD: 039013). It should be noted, however, that as the presence of $\mathrm{Al}_{4} \mathrm{~B}_{2} \mathrm{O}_{9}$ cannot be definitely excluded by the XRD pattern of the bulk sample, the alternative assignment of the $d$-spacing to the (1 111 ) plane of $\mathrm{Al}_{4} \mathrm{~B}_{2} \mathrm{O}_{9}$ (ICSD: 071113) cannot either. The presence of $\mathrm{Al}, \mathrm{B}$, and $\mathrm{O}$ was confirmed by SEM-EDX, and WDS measurements (Fig. S15 and $\mathrm{S} 16 \dagger)$. The $\sim 5 \mathrm{~nm}$ coating observed in Fig. $5 \mathrm{c}$ is probably a partially ordered layer of carbon covering the crystalline aluminum borate core; measurement by TEM-EDX revealed an 


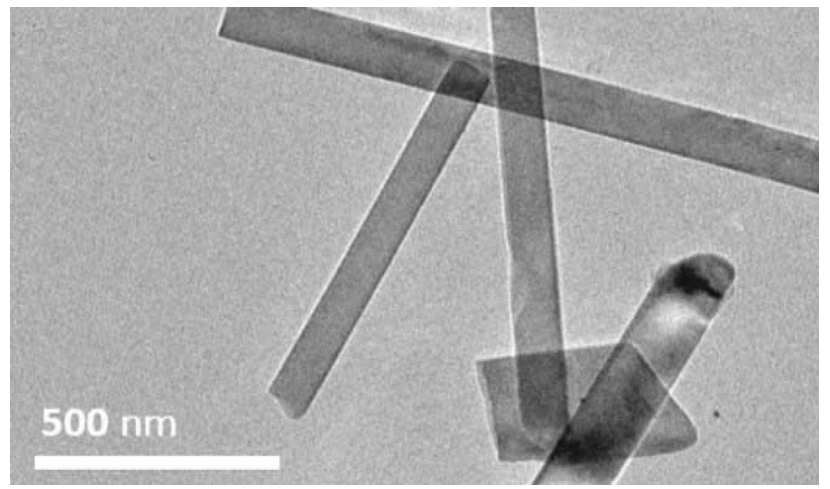

Fig. 6 TEM image of $\mathrm{Al}_{5} \mathrm{BO}_{9}$ nanoribbons grown from the pyrolysis $\left(2 \mathrm{~h}\right.$, at $1000{ }^{\circ} \mathrm{C}$ under flow of $\left.\mathrm{N}_{2}\right)$ of a (1:1 by mass) mixture of AIN powder and polyaminoborane 1 .

appreciable carbon content (Fig. S17†). Additionally, the presence of a low intensity peak at $2 \theta=26.5^{\circ}$, as observed in the XRD diffraction pattern (Fig. S13 $\dagger$ ) may be indexed to the $\left(\begin{array}{ll}0 & 0\end{array}\right.$ 2) plane of graphite (ICSD: 53781), further supporting our tentative assertion.

Similarly, pyrolysis $\left(2 \mathrm{~h}\right.$, at $1000{ }^{\circ} \mathrm{C}$ under flow of $\left.\mathrm{N}_{2}\right)$ of a (1:1 by mass) mixture of AlN powder and 1 was attempted. AlN buffer layers had previously been utilized by Chubarov et al. for the growth of rhombohedral-BN. ${ }^{18}$ However in our case, inclusion of AlN resulted in the formation of clusters of rectangular aluminum borate nanoribbons featuring widths in the 100-200 nm range, as observed by TEM (Fig. 6). As with the reaction on $\mathrm{Al}_{2} \mathrm{O}_{3}$, XRD measurements (Fig. S18 $\dagger$ ) revealed the presence of what is most likely $\mathrm{Al}_{5} \mathrm{BO}_{9}$ (ICSD: 039013) on account of the boron-content in 1 relative to $\mathrm{B} / \mathrm{B}_{2} \mathrm{O}_{3}$ and the product mixture observed when the latter was used as the feedstock. $^{17 a}$ The presence of $\mathrm{Al}, \mathrm{B}$, and $\mathrm{O}$ was confirmed by SEM-EDX and WDS measurements (Fig. S19 and S20 ${ }^{\dagger}$ ).

Finally, pyrolysis of polyaminoborane 2 on annealed sapphire wafer $\left(2 \mathrm{~h}\right.$, at $1300{ }^{\circ} \mathrm{C}$, under flow of $\mathrm{N}_{2}$, no induced defects) also resulted in the formation of aluminum borate nanowires and, in addition, nanotubes (Fig. S21†). Unlike previous trials utilizing $\mathbf{1}$ on defect-laden sapphire surface, the use of a smooth sapphire surface resulted in rectangular nanowires, which were significantly larger in size (some greater than $1000 \mathrm{~nm}$ in diameter) and appeared, in some cases, to be hollow (Fig. S21 $\dagger$ ). The XRD diffraction pattern (Fig. S22†) was again consistent with the orthorhombic phase of $\mathrm{Al}_{5} \mathrm{BO}_{9}$ (ICSD: 039013). The presence of $\mathrm{Al}, \mathrm{B}$, and $\mathrm{O}$ was similarly confirmed by SEM-EDX analysis (Fig. S23†).

\section{Discussion}

Bulk aluminum borates are attractive materials owing to their many useful properties, such as high strength, chemical inertness, high temperature stability, which includes resistance to oxidation at high temperatures and a low coefficient of thermal expansion. ${ }^{19}$ Moreover, one-dimensional nanostructures, such as nanowires, often have intriguing properties that differ from those of bulk materials. These include quantum confinement of electrons by the potential wells of nanometer-sized structures, which may allow control of electrical, optical, magnetic, and thermoelectric properties of solidstate functional materials. ${ }^{20}$ This has led to potential applications of aluminum borate nanostructures in ceramic composites, metal matrix composites, tribology, and as building blocks in optoelectronics. ${ }^{21}$

Surprisingly, polyaminoboranes 1 and 2 have proven to be excellent precursors for the facile fabrication of aluminum borate nanowires (via 1) and in some cases larger nanotubes (via 2) on sapphire substrates. The ability to use a stable, single-source precursor which can be delivered with ease via drop-casting on a substrate or mixed with a powder of $\mathrm{Al}_{2} \mathrm{O}_{3}$ or AlN for the synthesis of aluminium borate nanowires proves advantageous over more conventional techniques. Aluminum borate nanowire synthesis typically requires multiple reagents, catalysts, or more complex chemical vapour deposition (CVD) methodology with subsequent pyrolysis at temperatures ranging from $750-1100{ }^{\circ} \mathrm{C} .{ }^{22}$ In the instance of sapphire wafer as substrate, the size of the resulting nanowires was influenced by modifying the surface defect density. While pyrolysis of polyaminoboranes on smooth sapphire led to nanowires, and in some cases, nanotubes, with diameters greater than $1000 \mathrm{~nm}$, introducing surface defects produced nanowires with diameters in the 100-150 nm range.

Rümmeli and coworkers have recently reported the synthesis of $\mathrm{Al}_{4} \mathrm{~B}_{2} \mathrm{O}_{9}$ and $\mathrm{Al}_{5} \mathrm{BO}_{9}$ nanowires from the pyrolysis $\left(700-1100{ }^{\circ} \mathrm{C}\right.$ ) of a mixture of $\mathrm{B}$ and $\mathrm{B}_{2} \mathrm{O}_{3}$ (3:4 by mass) on sapphire wafers, ${ }^{17 a}$ a process reminiscent of our procedure. Samples pyrolyzed on smooth surfaces resulted in slower formation of larger diameter nanowires, whereas samples with defects (induced by incorporation of $\mathrm{Fe}_{3} \mathrm{O}_{4}$ nanoparticles) resulted in the facile formation of smaller diameter nanowires. The growth mechanism was attributed to diffusion of boron into the sapphire wafer, a process which occurs more readily at surface defects, followed by initial surface corrugation, and ultimately nanowire formation, which occurs as a measure to alleviate the stress build up from the resulting thermal expansion mismatch as aluminum oxide becomes aluminum borate. ${ }^{17 a}$ Thus, we propose a similar growth mechanism, whereby B-N based precursor (polyaminoborane 1 or 2) either decomposes, leading to diffusion of $\mathrm{B}$ into the alumina surface, or diffuses directly into the alumina surface, where $\mathrm{N}$ is released, and growth of aluminum borate nanowires begins. This is consistent with defect-laden sapphire resulting in smaller diameter nanowires, and smooth surface sapphire resulting in a slower formation of larger diameter nanowires; this is also consistent with previously reported observations. ${ }^{17 a}$

The fabrication of $\mathrm{Al}_{4} \mathrm{~B}_{2} \mathrm{O}_{9}$ nanowhiskers on the surface of aluminum powder with boric acid as boron source has recently been described by Shi and coworkers. ${ }^{22}$ It was proposed that during pyrolysis $\left(600-800{ }^{\circ} \mathrm{C}\right.$ ), boric acid decomposed to $\mathrm{B}_{2} \mathrm{O}_{3}$ 
and the $\mathrm{Al}_{2} \mathrm{O}_{3}$ layer formed on the aluminum powder dissolved into the liquid $\mathrm{B}_{2} \mathrm{O}_{3}\left(\mathrm{mp} 450{ }^{\circ} \mathrm{C}\right)$, initiating nanostructure growth. Overall, the formation of $\mathrm{Al}_{5} \mathrm{BO}_{9}$ nanowhiskers was described as a solution-liquid-solid (SLS) growth process. A similar process may operate for the $\mathrm{Al}_{5} \mathrm{BO}_{9}$ nanowire and nanoribbon growth processes described herein for mixtures of polyaminoborane 1 with $\mathrm{Al}_{2} \mathrm{O}_{3}$ or AlN powders. High temperature decomposition of $\mathbf{1}$, in contact with atmospheric $\mathrm{O}_{2}$ may lead to the generation of $\mathrm{B}_{2} \mathrm{O}_{3}$, which can interact with $\mathrm{Al}_{2} \mathrm{O}_{3}$, either already present, or generated from the high temperature reaction of AlN with atmospheric $\mathrm{O}_{2}$. Alternatively, the growth process may proceed in a similar manner to that described for the pyrolysis of polyaminoboranes on sapphire wafer (vide supra).

\section{Conclusions}

In the case of Si-wafer as substrate, the pyrolysis of 2 resulted in amorphous nanostructures which feature a component of h-BN. The use of rhodium foil as substrate afforded amorphous $\mathrm{B}$ and N-containing nanostructures from the pyrolysis of 1 and 2, and polydisperse, amorphous B and N-containing spherical nanoparticles from $\mathrm{H}_{3} \mathrm{~N} \cdot \mathrm{BH}_{3}$. Switching the substrate to sapphire wafers, as well as $\mathrm{Al}_{2} \mathrm{O}_{3}$ and AlN powders, resulted in the unexpected production of crystalline aluminum borate nanowires, most likely $\mathrm{Al}_{5} \mathrm{BO}_{9}$. In the instance of sapphire wafer substrates, the diameters of the resulting nanowires were dependent on the surface defect density. In the case of smooth surfaces, larger nanowires were produced, whereas defect-laden surfaces facilitated the formation of significantly smaller nanowires. The ability to use polyaminoboranes $\mathbf{1}$ and 2 as stable precursors to aluminum borate nanowires, which can be delivered with ease via drop-casting on a substrate, or mixing with a powder of $\mathrm{Al}_{2} \mathrm{O}_{3}$ or AlN appears to be potentially advantageous over conventional, more complex approaches (e.g. CVD). Optimisation and further development of this process is currently under investigation. We are also investigating polyaminoboranes that undergo thermallyinduced crosslinking in order to access BN-containing ceramics in higher yield.

\section{Acknowledgements}

V. A. D. thanks the Deutsche Forschungsgemeinschaft (DFG) for a Postdoctoral Fellowship. T. J. thanks the EU for a Marie Curie Postdoctoral Fellowship and EPSRC for support. I. M. also thanks the EPSRC for support. The authors thank the Electron Microscopy Unit (School of Chemistry, University of Bristol) for support with TEM measurements, and Dr B. Buse (School of Earth Sciences, University of Bristol) for support with WDS measurements. J. Gwyther (University of Bristol) is thanked for helpful discussions.

\section{References}

1 (a) A. Staubitz, A. P. M. Robertson and I. Manners, Chem. Rev., 2010, 110, 4079-4124; (b) A. Karkamkar, C. Aardahl and T. Autrey, Mater. Matters, 2007, 2, 6-10; available at http://www.sigmaaldrich.com/materials-science/learningcenter/material-matters.html (c) B. Peng and J. Chen, Energy Environ. Sci., 2008, 1, 479-483; (d) F. H. Stephens, V. Pons and R. T. Baker, Dalton Trans., 2007, 2613-2626; (e) N. C. Smythe and J. C. Gordon, Eur. J. Inorg. Chem., 2010, 509-521; $(f)$ O. T. Summerscales and J. C. Gordon, Dalton Trans., 2013, 42, 10075-10084; $(g)$ M. E. Bluhm, M. G. Bradley, R. Butterick III, U. Kusari and L. G. Sneddon, J. Am. Chem. Soc., 2006, 128, 7748-7749; (h) D. W. Himmelberger, C. W. Yoon, M. E. Bluhm, P. J. Carroll and L. G. Sneddon, J. Am. Chem. Soc., 2009, 131, 14101-14110.

2 (a) A. Staubitz, A. P. M. Robertson, M. E. Sloan and I. Manners, Chem. Rev., 2010, 110, 4023-4078; (b) E. M. Leitao, N. E. Stubbs, A. P. M. Robertson, H. Helten, R. J. Cox, G. C. Lloyd-Jones and I. Manners, J. Am. Chem. Soc., 2012, 134, 16805-16816; (c) M. E. Sloan, A. Staubitz, K. Lee and I. Manners, Eur. J. Org. Chem., 2011, 672-675; (d) X. Yang, L. Zhao, T. Fox, Z.-X. Wang and H. Berke, Angew. Chem., Int. Ed., 2010, 49, 2058-2062; (e) X. Yang, T. Fox and H. Berke, Chem. Commun., 2011, 47, 2053-2055; $(f)$ C. C. Chong, H. Hirao and R. Kinjo, Angew. Chem., Int. Ed., 2014, 53, 3342-3346.

3 (a) E. M. Leitao, T. Jurca and I. Manners, Nat. Chem., 2013, 5, 817-829; (b) A. Staubitz, A. Presa Soto and I. Manners, Angew. Chem., Int. Ed., 2008, 47, 6212-6215; (c) A. Staubitz, M. E. Sloan, A. P. M. Robertson, A. Friedrich, S. Schneider, P. J. Gates, J. Schmedt auf der Günne and I. Manners, J. Am. Chem. Soc., 2010, 132, 13332-13345; (d) A. N. Marziale, A. Friedrich, I. Klopsch, M. Drees, V. R. Celinski, J. Schmedt auf der Günne and S. Schneider, J. Am. Chem. Soc., 2013, 135, 13342-13355; (e) H. C. Johnson, E. M. Leitao, G. R. Whittell, I. Manners, G. C. Lloyd-Jones and A. S. Weller, J. Am. Chem. Soc., 2014, 136, 9078-9093.

4 (a) N. G. Chopra, R. J. Luyken, K. Cherrey, V. H. Crespi, M. L. Cohen, S. G. Louie and A. Zettl, Science, 1995, 269, 966-967; (b) K. F. Huo, Z. Hu, F. Chen, J. J. Fu, Y. Chen, B. H. Liu, J. Ding, Z. L. Dong and T. White, Appl. Phys. Lett., 2002, 80, 3611-3613; (c) Y. Kubota, K. Watanabe, O. Tsuda and T. Taniguchi, Science, 2007, 317, 932-934; (d) M. Corso, W. Auwärter, M. Muntwiler, A. Tamai, T. Greber and J. Osterwalder, Science, 2004, 303, 217-220.

5 K. S. Novoselov, A. K. Geim, S. V. Morozov, D. Jiang, Y. Zhang, S. V. Dubonos, I. V. Grigorieva and A. A. Firsov, Science, 2004, 306, 666-669.

6 (a) G. R. Whittell and I. Manners, Angew. Chem., Int. Ed., 2011, 50, 10288-10289; (b) D. Golberg, Y. Bando, Y. Huang, T. Terao, M. Mitome, C. Tang and C. Zhi, ACS Nano, 2010, 4, 2979-2993; (c) K. K. Kim, A. Hsu, X. Jia, S. M. Kim, Y. Shi, M. Dresselhaus, T. Palacios and J. Kong, ACS Nano, 2012, 6, 8583-8590. 
7 Selected examples: (a) R. T. Paine and C. K. Narula, Chem. Rev., 1990, 90, 73-91; (b) A. Ismach, H. Chou, D. A. Ferrer, Y. Wu, S. McDonnell, H. C. Floresca, A. Covacevich, C. Pope, R. Piner, M. J. Kim, R. M. Wallace, L. Colombo and R. S. Ruoff, ACS Nano, 2012, 6, 6378-6385; (c) S. Schlienger, J. Alauzun, F. Michaux, L. Vidal, J. Parmentier, C. Gervais, F. Babonneau, S. Bernard, P. Miele and J. B. Parra, Chem. Mater., 2012, 24, 88-96; (d) J. Li, S. Bernard, V. Salles, C. Gervais and P. Miele, Chem. Mater., 2010, 22, 2010-2019; (e) A. Nag, K. Raidongia, K. P. S. S. Hembram, R. Datta, U. V. Waghmare and C. N. R. Rao, ACS Nano, 2010, 4, 15391544; $(f)$ S. K. Kim, H. Cho, M. J. Kim, H. J. Lee, J. Park, Y.-B. Lee, H. C. Kim, C. W. Yoon, S. W. Nam and S. O. Kang, J. Mater. Chem. A, 2013, 1, 1976-1981; (g) D.-P. Kim, K.-T. Moon, J.-G. Kho, J. Economy, C. Gervais and F. Babonneau, Polym. Adv. Technol., 1999, 10, 702-712; (h) L. G. Sneddon, M. G. L. Mirabelli, A. T. Lynch, P. J. Fazen, K. Su and J. S. Beck, Pure Appl. Chem., 1991, 63, 407-410; (i) P. J. Fazen, E. E. Remsen, J. S. Beck, P. J. Carroll, A. R. McGhie and L. G. Sneddon, Chem. Mater., 1995, 7, 1942-1956; (j) T. Wideman, P. J. Fazen, K. Su, E. E. Remsen, G. A. Zank and L. G. Sneddon, Appl. Organomet. Chem., 1998, 12, 681-693; (k) S. Bernard and P. Miele, Materials, 2014, 7, 7436-7459.

8 A. B. Pangborn, M. A. Giardello, R. H. Grubbs, R. K. Rosen and F. J. Timmers, Organometallics, 1996, 15, 1518-1520.

9 I. Göttker-Schnetmann, P. S. White and M. Brookhart, Organometallics, 2004, 23, 1766-1776.

10 Due to the poor solubility of $\mathbf{1}$ in THF, this material was cast as a dispersion. This caused an uneven distribution of 1, and as a result, a higher surface area and less substrate contact, which probably explains the negligible ceramic yield. Conversely, polyaminoborane 2 displayed excellent solubility in THF, and could be dropcast as a coherent thin film.

11 For iron-catalysed dehydrocoupling see: (a) J. R. Vance, A. P. M. Robertson, K. Lee and I. Manners, Chem. - Eur. J., 2011, 17, 4099-4103; (b) J. R. Vance, A. Schäfer, A. P. M. Robertson, K. Lee, J. Turner, G. R. Whittell and I. Manners, J. Am. Chem. Soc., 2014, 136, 3048-3064; (c) R. T. Baker, J. C. Gordon, C. W. Hamilton, N. J. Henson, P.-H. Lin, S. Maguire, M. Murugesu, B. L. Scott and N. C. Smythe, J. Am. Chem. Soc., 2012, 134, 5598-5609; (d) C. Lichtenberg, L. Viciu, M. Adelhardt, J. Sutter, K. Meyer, B. de Bruin and H. Grützmacher, Angew. Chem., Int. Ed., 2015, 54, 5766-5771. For nickel-catalysed dehydrocoupling see: (e) A. P. M. Robertson, R. Suter, L. Chabanne, G. R. Whittell and I. Manners, Inorg. Chem., 2011, 50, 12680-12691; $(f)$ R. J. Keaton, J. M. Blacquiere and R. T. Baker, J. Am. Chem. Soc., 2007, 129, 1844-1845; (g) M. Vogt, B. de Bruin, H. Berke, M. Trincado and H. Grützmacher, Chem. Sci., 2011, 2, 723-727.

12 (a) Boron-nitride nanowires grown on stainless-steel substrate from a mixture of $\mathrm{B}$ and $\mathrm{ZnO}$ at $1100{ }^{\circ} \mathrm{C}$ under a mixture of $\mathrm{H}_{2}$ and $\mathrm{N}_{2}$ : Y. J. Chen, B. Chi, D. C. Mahon and
Y. Chen, Nanotechnology, 2006, 17, 2942-2946; (b) Heteroepitaxial layers of h-BN grown from triethylboron and ammonia on single crystal $\mathrm{Ni}(111)$ substrates at $1020{ }^{\circ} \mathrm{C}$ : Y. Kobayashi, T. Nakamura, T. Akasaka, T. Makimoto and N. Matsumoto, Phys. Status Solidi B, 2007, 244, 1789-1792; (c) Chemical vapour deposition of $\mathrm{BN}$ nanosheets on $\mathrm{Cu}$, and $\mathrm{Ni}(111)$ from decaborane under a flow of $\mathrm{N}_{2}$ and $\mathrm{H}_{2}$ at $1000{ }^{\circ} \mathrm{C}$ : S. Chatterjee, Z. Luo, M. Acerce, D. M. Yates, A. T. C. Johnson and L. G. Sneddon, Chem. Mater., 2011, 23, 4414-4416; (d) Boron-nitride nanotubes synthesized with the aid of floating nickel catalyst via catalytic chemical vapour deposition (CCVD) of either borazine $\left(\mathrm{B}_{3} \mathrm{~N}_{3} \mathrm{H}_{6}\right)$ or decaborane at $1200-1300{ }^{\circ} \mathrm{C}$ : S. Chatterjee, M. J. Kim, D. N. Zakharov, S. M. Kim, E. A. Stach, B. Maruyama and L. G. Sneddon, Chem. Mater., 2012, 24, 2872-2879; (e) Boron-nitride nanotubes grown by CVD method utilizing $\mathrm{Ni}, \mathrm{NiB}$, or $\mathrm{Ni}_{2} \mathrm{~B}$ particles as catalyst at 1000-1100 ${ }^{\circ} \mathrm{C}$ : O. R. Lourie, C. R. Jones, B. M. Bartlett, P. C. Gibbons, R. S. Ruoff and W. E. Buhro, Chem. Mater., 2000, 12, 1808-1810.

13 The change in morphology is probably due to the onset of respective metal oxide nanoparticle growth at the high pyrolysis temperatures utilized $\left(1000{ }^{\circ} \mathrm{C}\right)$. In addition, the presence of amine-borane materials, may also contribute to the process via interactions with the substrate surface, causing defects which seed metal oxide growth. The presence of oxygen was confirmed by SEM-EDX, see Fig. S7 and $\mathrm{S} 8 . \dagger$

14 (a) C. A. Jaska, K. Temple, A. J. Lough and I. Manners, Chem. Commun., 2001, 962-963; (b) C. A. Jaska, K. Temple, A. J. Lough and I. Manners, J. Am. Chem. Soc., 2003, 125, 9424-9434; (c) T. M. Douglas, A. B. Chaplin, A. S. Weller, X. Yang and M. B. Hall, J. Am. Chem. Soc., 2009, 131, 15440-15456; (d) L. J. Sewell, G. C. Lloyd-Jones and A. S. Weller, J. Am. Chem. Soc., 2012, 134, 3598-3610; (e) H. C. Johnson and A. S. Weller, Angew. Chem., Int. Ed., 2015, 54, 10173-10177.

15 (a) D. A. Lindquist, T. T. Kodas, D. M. Smith, X. M. Xiu, S. L. Hietala and R. T. Paine, J. Am. Ceram. Soc., 1991, 74, 3126-3128; (b) C. Tang, Y. Bando and D. Golberg, Chem. Commun., 2002, 2826-2827; (c) C. Tang, Y. Bando, Y. Huang, C. Zhi and D. Golberg, Adv. Funct. Mater., 2008, 18, 3653-3661.

16 K. Nakamura, Electrochem. Soc., 1986, 133, 1120-1123.

17 (a) I. Gonzalez-Martinez, A. Bachmatiuk, S. Gorantla, J. Kunstmann, V. Bezugly, T. Gemming, B. Büchner, G. Cuniberti and M. H. Rümmeli, J. Appl. Phys., 2012, 112, 024308; (b) D. Tsivion, M. Schvartzman, R. Popovitz-Biro and E. Joselevich, ACS Nano, 2012, 6, 6433-6445.

18 M. Chubarov, H. Pedersen, H. Högberg, J. Jensen and A. Henry, Cryst. Growth Des., 2012, 12, 3215-3220.

19 (a) K. Suganuma, T. Fujita, N. Suzuki and K. Niihara, J. Mater. Sci. Lett., 1990, 9, 633-635; (b) R. Ma, Y. Bando, T. Sato, C. Tang and F. Xu, J. Am. Chem. Soc., 2002, 124, 10668-10669; (c) H. S. Song, E. M. Elssfah, J. Zhang, J. Lin, J. J. Luo, S. J. Liu, Y. Huang, X. X. Ding, J. M. Gao, S. R. Qi 
and C. Tang, J. Phys. Chem. B, 2006, 110, 5966-5969; (d) M. Zheng, K. Wu, H. Liang, S. Kamado and Y. Kojima, Mater. Lett., 2002, 57, 558-564.

20 See: Y. Xia, P. Yang, Y. Sun, Y. Wu, B. Mayers, B. Gates, Y. Yin, F. Kim and H. Yan, Adv. Mater., 2003, 15, 353-389, and references therein.

21 (a) L. M. Peng, S. J. Zhu, Z. Y. Ma, J. Bi, F. G. Wang, H. R. Chen and D. O. Northwood, Mater. Sci. Eng., A, 1999, 265, 63-70; (b) Z. S. Hu, Y. G. Shi, L. G. Wang, Y. Peng, G. X. Chen and J. X. Dong, Lubr. Eng., 2001, 57, 23-27; (c) R. Ma, Y. Bando and T. Sato, Appl. Phys. Lett., 2002, 81, 3467-3469; (d) X. Tao, X. Wang and X. Li, Nano Lett., 2007, 7, 3172-3176; (e) E. M. Elssfah, H. S. Song, C. C. Tang, J. Zhang, X. X. Ding and S. R. Qi, Mater. Chem. Phys., 2007,
101, 499-504; $(f)$ R. K. Gupta, A. A. Al-Ghamdi, O. A. AlHartomy, F. Al-Hazmi, F. El-Tantawy and F. Yakuphanoglu, J. Sol-Gel Sci. Technol., 2012, 64, 100-103; (g) Y. Li and R. P. H. Chang, Mater. Chem. Phys., 2006, 97, 23-30; (h) J. Wang, G. Ning, X. Yang, Z. Gan, H. Liu and Y. Lin, Mater. Lett., 2008, 62, 1208-1211; (i) S. H. Kenawy, Int. J. Appl. Ceram. Technol., 2011, 8, 783-792; (j) Y. Liu, Q. Li and S. Fan, Chem. Phys. Lett., 2003, 375, 632-635; (k) L. M. Peng, X. K. Li, H. Li, J. H. Wang and M. Gong, Ceram. Int., 2006, 32, 365-368; (l) H.-T. Sun, F. Shimaoka, M. Fujii, N. Nitta, M. Mizuhata, H. Yasuda, S. Deki and S. Hayashi, Nanotechnology, 2009, 20, 035604.

22 Z. Yu, N. Zhao, E. Liu, C. Shi, X. Du and J. Wang, Powder Technol., 2011, 212, 310-315. 